\title{
Psychoactive Substance Use among Second-Year and Third-Year Medical Students of a Medical College: A Descriptive Cross-sectional Study
}

\author{
Alisha Sapkota, ${ }^{1}$ Vinutha Silvanus, ${ }^{2}$ Priyanka Shah, ${ }^{1}$ Sanjeev Chandra Gautam, ${ }^{3}$ Anjeel Chhetri ${ }^{4}$ \\ 'Nepal Medical College and Teaching Hospital, Kathmandu, Nepal, ${ }^{2}$ Department of Community Medicine, Nepal \\ Medical College and Teaching Hospital, Kathmandu, Nepal, ${ }^{3}$ Department of Psychiatry, Nepal Medical College and \\ Teaching Hospital, Kathmandu, Nepal, ${ }^{4}$ Department of Psychiatry, Devdaha Medical College, Devdaha, Nepal.
}

\section{ABSTRACT}

Introduction: Psychoactive substance use among medical students is common. This may not only pose a threat to their health and academic performance but may have medico-legal and ethical ramifications. The aim of this study was to find out the prevalence of six psychoactive substances (alcohol, tobacco, cannabis, cocaine, benzodiazepines, opioids) among second year and third year medical students.

Methods: A descriptive cross-sectional study was done in a medical college. Whole sampling was done and ethical approval was taken from the Institutional Review Committee (Reference Number: 54-074/075). The study was conducted from May 2018 to June 2018. A semi-structured self-administered questionnaire modified and adapted from World Health Organization's guidelines for student substance use survey was used to collect data from second year and third year medical students. Statistical Package for Social Sciences version 16.0 was used for analysis. Point estimate at 95\% Confidence Interval was calculated along with frequency and proportion for binary data.

Results: Out of 226 total respondents, 95 (42.0\%) (35.55- 48.45 at 95\% Confidence Interval) reported current use of one or more psychoactive substances. Most frequently used substance was alcohol with current use prevalence of 87 (38.5\%), followed by smoking 39 (17.3\%) and cannabis $27(11.9 \%)$. Cocaine, benzodiazepines and opioids were the least consumed substances with current use prevalence of $2(0.9 \%)$ each.

Conclusions: Almost half of the students were currently using one or more psychoactive substances which is concerning, and therefore strategies must be adopted to alleviate such use.

Keywords: alcohol; cannabis; medical students; smoking; substance use.

\section{INTRODUCTION}

The World Health Organization (WHO) defines psychoactive substances as, "substances that, when taken in or administered into one's system, affect mental processes, e.g. perception, consciousness, cognition or mood and emotions."1 Psychoactive substance use has been increasing globally, owing to the modification in lifestyles and increasing acceptance of use of such substances in general public. ${ }^{2}$

Psychoactive substance use is common among medical students. ${ }^{2}$ Recurrent and prolonged use may ultimately result in abuse and dependency. ${ }^{3}$ This can pose a negative impact on the health and academic performance of students, while also having medico- legal and ethical consequences. ${ }^{4,5}$

The aim of this study is to find out the prevalence of psychoactive substance use among second year and third year medical students. This study focuses on six types of psychoactive substances like- alcohol, tobacco, cannabis, cocaine, benzodiazepines and opioids.

\section{METHODS}

This was a descriptive cross-sectional study done on

Correspondence: Dr. Alisha Sapkota, Nepal Medical College and Teaching Hospital, Kathmandu, Nepal. Email: alishasapkota@gmail.com, Phone: +977-9849151278. 
second and third year students of a medical college located in Kathmandu Valley from May 2018 to June 2018, using the whole sampling method. Ethical approval was taken from the Research and Institutional Review Committee (IRC) of NMCTH (Reference Number: 54-074/075).

The minimum sample size required for the study was calculated as follow:

$$
\begin{aligned}
\mathrm{n} & =\mathrm{Z}^{2} \times(\mathrm{p} \times \mathrm{q}) / \mathrm{e}^{2} \\
& =(1.96)^{2} \times 0.5 \times 0.5 /(0.07)^{2} \\
& =196
\end{aligned}
$$

where,

$\mathrm{n}=$ minimum sample size

$\mathrm{Z}=1.96$ at $95 \%$ Confidence Interval $(\mathrm{Cl})$

$\mathrm{p}=$ prevalence taken as $50 \%$ for maximum sample size $q=(1-p)$

$\mathrm{e}=$ margin of error, $7 \%$

Total sample size was calculated to be 196. Adding $10 \%$ non respondence rate the sample size becomes 216 . However we took a sample size of 226 in our study.

A semi-structured self-administered questionnaire modified and adapted from WHO's guidelines for student substance use survey was used. ${ }^{6}$ Before being finalized, the questionnaire was also pretested on a group of medical students who were not part of the actual survey. The questionnaire included information on prevalence of lifetime substance use (any use during a person's life), use in the last 12 months (recent use) and use in the last 30 days (current use) of six psychoactive substances: alcohol, tobacco, cannabis, cocaine, benzodiazepines and opioids. It included information on socio demographic factors including age, sex, year of study, current place of residence and academic performance in medical school. Academic performance was assessed based on students' own rating. Second and third year medical students were contacted after their class hours, and were invited to participate in the survey. Verbal informed consent was taken from all the students participating in the survey. Assurance regarding confidentiality of the responses was provided and maintained. The students were allowed to ask questions in order to clarify any confusion or misunderstanding. After completing the questionnaire, the participants were asked to put the filled questionnaire in a box placed in front of the classroom. Out of 250 questionnaires distributed, 226 were received with response rate of $90.4 \%$. The terms 'psychoactive substance use' and 'substance use' have been interchangeably used in this research.

Data entry and analysis was done using Statistical Package for the Social Sciences version 16. Statistical tools such as frequency, percentage, median and interquartile range and Confidence Interval at $95 \%$ were used.

\section{RESULTS}

Among the 226 respondents, 95 (42.0\%) (35.55- 48.45 at $95 \% \mathrm{Cl}$ ) respondents reported current use (use in the last 30 days) of one or more substances. Seventy-one $(60.2 \%)$ males and 24 (22.2\%) females reported current use. The most currently used substance was alcohol with current use prevalence of 87 (38.5\%) followed by tobacco $39(17.2 \%)$ and cannabis $27(11.9 \%)$. Cocaine, benzodiazepine and opioid were the least consumed substances, with current use prevalence being 2 (0.9\%). Three $(1.3 \%)$ students reported recent use of cocaine

\begin{tabular}{|c|c|c|c|c|c|c|}
\hline & $\begin{array}{l}\text { Lifetime } \\
\text { Alcohol use } \\
\text { n (\%) }\end{array}$ & $\begin{array}{l}\text { Lifetime } \\
\text { Tobacco use } \\
\text { n (\%) }\end{array}$ & $\begin{array}{l}\text { Lifetime } \\
\text { Cannabis } \\
\text { use } n(\%)\end{array}$ & $\begin{array}{l}\text { Lifetime } \\
\text { Cocaine } \\
\text { use } n(\%)\end{array}$ & $\begin{array}{l}\text { Lifetime } \\
\text { Benzodiazepine } \\
\text { use } n(\%)\end{array}$ & $\begin{array}{l}\text { Lifetime } \\
\text { Opioid use n } \\
\text { (\%) }\end{array}$ \\
\hline Males $(n=118)$ & $95(80.5)$ & $54(45.8)$ & $35(29.7)$ & $1(0.8)$ & $2(1.7)$ & $1(0.8)$ \\
\hline Females $(n=108)$ & $67(62.0)$ & $9(8.3)$ & $7(6.5)$ & $2(1.9)$ & $1(0.9)$ & $2(1.9)$ \\
\hline \multirow[t]{2}{*}{ Total $(n=226)$} & 162 (71.7) & 63 (27.9) & $42(18.6)$ & $3(1.3)$ & $3(1.3)$ & $3(1.3)$ \\
\hline & $\begin{array}{l}\text { Recent } \\
\text { Alcohol use } \\
\text { n (\%) }\end{array}$ & $\begin{array}{l}\text { Recent } \\
\text { Tobacco use } \\
\text { n (\%) }\end{array}$ & $\begin{array}{l}\text { Recent } \\
\text { Cannabis } \\
\text { use } \mathrm{n}(\%)\end{array}$ & $\begin{array}{l}\text { Recent } \\
\text { Cocaine } \\
\text { use } \mathrm{n}(\%)\end{array}$ & $\begin{array}{l}\text { Recent } \\
\text { Benzodiazepine } \\
\text { use } \mathrm{n}(\%)\end{array}$ & $\begin{array}{l}\text { Recent } \\
\text { Opioid use n } \\
\text { (\%) }\end{array}$ \\
\hline Males ( $n=118)$ & $88(74.6)$ & $49(41.5)$ & $32(27.1)$ & $1(0.8)$ & $2(1.7)$ & $1(0.8)$ \\
\hline Females $(n=108)$ & $60(55.6)$ & 8 (7.4\%) & $6(5.6)$ & $2(1.9)$ & $1(0.9)$ & $1(0.9)$ \\
\hline Total $(n=226)$ & 148 (65.5) & $57(25.2)$ & $38(16.8)$ & $3(1.3)$ & $3(1.3)$ & $2(0.9)$ \\
\hline
\end{tabular}
(use in the last one year); two $(0.9 \%)$ were found to be using it currently and both were females (Table 1). 
Sapkota et al. Psychoactive Substance Use among Second-Year and Third-Year Medical Students of a Medical College...

\begin{tabular}{|lllllll|}
\hline & $\begin{array}{l}\text { Current } \\
\text { Alcohol use } \\
\mathbf{n}(\%)\end{array}$ & $\begin{array}{l}\text { Current } \\
\text { Tobacco use } \\
\mathbf{n}(\%)\end{array}$ & $\begin{array}{l}\text { Current } \\
\text { Cannabis } \\
\text { use } \mathbf{n}(\%)\end{array}$ & $\begin{array}{l}\text { Current } \\
\text { Cocaine } \\
\text { use } \mathbf{n}(\%)\end{array}$ & $\begin{array}{l}\text { Current } \\
\text { Benzodiazepine } \\
\text { use } \mathbf{n}(\%)\end{array}$ & $\begin{array}{l}\text { Current } \\
\text { Opioid use } \\
\mathbf{n}(\%)\end{array}$ \\
Males $(\mathbf{n = 1 1 8 )}$ & $63(53.4)$ & $38(32.2)$ & $24(20.3)$ & $0(0.0)$ & $1(0.8)$ & $1(0.8)$ \\
Females $(\mathbf{n = 1 0 8 )}$ & $24(22.2)$ & $1(0.9)$ & $3(2.8)$ & $2(1.9)$ & $1(0.9)$ & $1(0.9)$ \\
Total $(\mathbf{n = 2 2 6 )}$ & $87(38.5)$ & $39(17.3)$ & $27(11.9)$ & $2(0.9)$ & $2(0.9)$ & $2(0.9)$ \\
\hline
\end{tabular}

Overall, 226 students completed the questionnaire with a response rate of $90.4 \%$. The age of the students ranged from 18 to 26 years with median age being 22.0 (Interquartile Range=3). (Table 2)

\begin{tabular}{|ll|}
\hline $\begin{array}{l}\text { Table 2. Socio demographic profile of the } \\
\text { respondents }(\mathbf{n}=\mathbf{2 2 6}) \text {. }\end{array}$ \\
\hline Categories & $\mathrm{n}(\%)$ \\
Gender & $118(52.2)$ \\
Males & $108(47.8)$ \\
Females & \\
Year of study & $82(36.3)$ \\
Second year & $144(63.7)$ \\
Third year & \\
Current place of stay & $178(78.8)$ \\
Hostel/Flat & $48(21.2)$ \\
Family home & \\
Academic performance & $61(27.0)$ \\
Good & $147(65.0)$ \\
Average & $18(8.0)$ \\
\hline Poor &
\end{tabular}

Among the current users of alcohol, 63 (72.4\%) were males and 24 (27.6\%) were females; current alcohol use being higher in males. Majority of current alcohol users reported using it 1-5 days in the last 30 days, the prevalence being $58(66.7 \%)$, whereas $19(21.8 \%)$ of the current alcohol users were found to be using it 20 or more days in the last 30 days. Although the percentage of females currently using alcohol was lesser than males, the percentage of those taking alcohol 20 or more days in the last 30 days was $33.3 \%$ which is higher compared to males, which was $17.5 \%$ (Table 3 ).

Among the current tobacco users, 38 (97.4\%) were males and 15 (39.5\%) of those reported using tobacco 20 or more days in the last 30 days. Only one female reported current use of tobacco. Among the current tobacco users, $14(35.9 \%)$ started using it before joining medical school, whereas 25 (64.1\%) started using it after joining medical school (Table 3).

Twenty four $(88.9 \%)$ of current cannabis users were males. Among the males, 18 (75.0\%) of them reported consuming cannabis $1-5$ days in the last 30 days. Three females reported current use of cannabis, and all of them reported using it 1-5 days in the last 30 days. Among the current cannabis users, 20 (74.1\%) started using it after joining medical school (Table 3).

\begin{tabular}{|c|c|c|c|c|}
\hline & $\begin{array}{l}\text { Current } \\
\text { users }\end{array}$ & $\begin{array}{l}1-5 \text { days in the last } \\
30 \text { days }\end{array}$ & $\begin{array}{l}6-19 \text { days in the last } \\
30 \text { days }\end{array}$ & $\begin{array}{l}20 \text { or more days in the } \\
\text { last } 30 \text { days }\end{array}$ \\
\hline & $\mathbf{n}$ & n (\%) & n (\%) & n (\%) \\
\hline Alcohol & 87 & $58(66.7)$ & $10(11.5)$ & $19(21.8)$ \\
\hline \multicolumn{5}{|l|}{ Gender } \\
\hline Males & 63 & $43(68.3)$ & $9(14.3)$ & $11(17.5)$ \\
\hline Females & 24 & $15(62.5)$ & $1(4.2)$ & $8(33.3)$ \\
\hline \multicolumn{5}{|l|}{ Year of Study } \\
\hline Second year & 27 & $11(40.7)$ & $4(14.8)$ & $12(44.4)$ \\
\hline Third year & 60 & $47(78.3)$ & $6(10.0)$ & $7(11.7)$ \\
\hline \multicolumn{5}{|l|}{ Start of alcohol use } \\
\hline Before joining medical school & 49 & $33(67.3)$ & $4(8.2)$ & $12(24.5)$ \\
\hline After joining medical school & 38 & $25(65.8)$ & $6(15.8)$ & $7(18.4)$ \\
\hline Tobacco & 39 & $17(43.6)$ & $7(18.0)$ & $15(38.4)$ \\
\hline \multicolumn{5}{|l|}{ Gender } \\
\hline Males & 38 & $17(44.7)$ & $6(15.8)$ & $15(39.5)$ \\
\hline Females & 1 & $0(0.0)$ & $1(100.0)$ & $0(0.0)$ \\
\hline \multicolumn{5}{|l|}{ Year of Study } \\
\hline Second year & 14 & $5(35.7)$ & $4(28.6)$ & $5(35.7)$ \\
\hline Third year & 25 & $12(48.0)$ & $3(12.0)$ & $10(40.0)$ \\
\hline
\end{tabular}


Sapkota et al. Psychoactive Substance Use among Second-Year and Third-Year Medical Students of a Medical College...

\begin{tabular}{|lllll|}
\hline Start of tobacco use & & & & \\
Before joining medical school & 14 & $5(35.7)$ & $2(14.3)$ & $7(50.0)$ \\
After joining medical school & 25 & $12(48.0)$ & $5(20.0)$ & $8(32.0)$ \\
Cannabis & 27 & $21(77.8)$ & $3(11.1)$ & $3(11.1)$ \\
Gender & & & & \\
Males & 24 & $18(75.0)$ & $3(12.5)$ & $3(12.5)$ \\
Females & 3 & $3(100.0)$ & $0(0.0)$ & $0(0.0)$ \\
Year of Study & & & & \\
Second year & 9 & $7(77.8)$ & $0(0.0)$ & $2(22.2)$ \\
Third year & 18 & $14(77.8)$ & $3(16.7)$ & $1(5.6)$ \\
Start of cannabis use & & & & $2(28.6)$ \\
Before joining medical school & 7 & $4(57.1)$ & $1(14.3)$ & $1(5.0)$ \\
After joining medical school & 20 & $17(85.0)$ & $2(10.0)$ & \\
\hline
\end{tabular}

\section{DISCUSSION}

In the present study, the total number of respondents was 226. Forty-two percent of all respondents reported current use of one or more psychoactive substances among which $74.7 \%$ were males and $25.3 \%$ were females. Prevalence of current use of substance among male respondents was $60.2 \%$ and among female respondents was $22.2 \%$. This finding is similar to an earlier study done by Budhathoki et $\mathrm{al}^{7}$ among medical students in Nepal which showed that the prevalence of substance use was $49.6 \%$. Another study conducted by Makanjuola et $\mathrm{al}^{8}$ done among Nigerian medical students, reported that $40.4 \%$ of all respondents were currently using one or more substances; current use among male and female respondents was $44 \%$ and $33 \%$ respectively. There seems to be a difference in prevalence rate of substance use among males and females, not only in our study but in many similar studies conducted in the past., $2,5,7-8$ This difference could be due to relatively greater social acceptability of substance use among males including other gender norms. $^{9}$

In our study, the most frequently used substance (both lifetime and current use) was alcohol with current use prevalence of $38.5 \%$ followed by tobacco (17.3\%). Similar findings were reported in studies conducted in Nepal in the past. ${ }^{2,7}$ This could be due to easier accessibility, affordability and minimal legal hindrances involving alcohol and tobacco compared to other substances. ${ }^{10}$ Moreover, alcohol is also used as a part of social and cultural practice among various ethnic groups in Nepal. ${ }^{11}$ Alcohol is extensively served in gatherings and festivals in different ethnic communities, and home brewing of alcohol is also fairly common. ${ }^{12-13}$ This coupled with limited legal regulations regarding the use and sales of alcohol could also be one of the factors that have led to its increased use among medical students in Nepal. ${ }^{14}$

According to the National Institute on Alcohol Abuse and Alcoholism (NIAAA), up to three drinks on a single day and up to seven drinks per week have been defined as low-risk drinking in women. For men, up to four drinks on a single day and up to 14 drinks per week is defined as low-risk drinking. ${ }^{15}$ Fortunately, in our study, a majority of current alcohol users were using it for only 1-5 days in the last 30 days. This although, not very concerning could pose a future risk of increased use of alcohol and therefore shouldn't be dismissed.

Five-point one percent of the global burden of disease has been attributed to the harmful use of alcohol. Furthermore, according to WHO, alcohol is considered to be the major risk factor for premature death and disability among people aged 15 to $49 .{ }^{16}$ In our study, $21.8 \%$ of current alcohol users were using it more than 20 days in the last 30 days which could be indicative of harmful drinking and is therefore concerning.

The current use of alcohol was found to be higher in males than females. Besides psychosocial factors, the gender difference in alcohol metabolism could also be a reason for this. Alcohol metabolism in males is more efficient than in females because males have highly active forms of Alcohol Dehydrogenase (ADH) in the stomach and liver. ${ }^{17}$ Females also tend to have lower body mass and a higher proportion of fat to muscle. Thus, females have a higher concentration of alcohol in their blood than adult men with the same amount of alcohol intake. ${ }^{18}$ Even with significantly lower alcohol exposure, females can have alcohol-related physical illnesses and can display more severe cognitive and motor impairment. ${ }^{19}$ In our study, there was a higher percentage of females consuming alcohol 20 or more days in the last 30 days compared to males, which is a significant finding.

Among the total current cannabis users, our study showed that the majority (74.1\%) started using it after joining medical school. A similar finding was noted in research done by Budhathoki et $\mathrm{al}^{7}$ which showed that all of the cannabis users started using it after joining 
medical school.

Although the frequency of substance use has been clearly presented, the exact quantification of the amount of substance used couldn't be assessed, which remains a limitation of our study. This study was also conducted on a single institution on a limited number of students, so the results cannot be generalized, and since this study is cross-sectional, a causal relationship could not be established. Therefore, we recommend longitudinal study to be carried out with a larger group of students involving multiple institutions.

\section{CONCLUSIONS}

Almost half of the students in our study were currently using one or more substances, with male predominance. Continued use can have implications on their academic performance and health. Therefore, strategies must be adopted to limit the use of substance, some of which include raising awareness regarding the ill effects of substance use beginning from the first year, imposing and strengthening rules against the use and sale of easily available substances like tobacco and alcohol around college and hospital premises, encouraging engagement in extra-curricular activities like sports, which can serve as a break from the daily stress of student life and also setting up screening facilities within medical colleges.

\section{ACKNOWLEDGEMENTS}

We would like to thank the Department of Community Medicine of Nepal Medical College for their continuous support and encouragement.

Conflict of Interest: None.

\section{REFERENCES}

1. World Health Organization (WHO). Drugs (psychoactive) [Internet]. Geneva, World Health Organization; 2021 [cited 2021 Apr 7]. Available from: https://www.who.int/ health-topics/drugs-psychoactive\#tab=tab_3. [Full Text]

2. Khanal P, Ghimire RH, Gautam B, Dhungana SK, Parajuli P, Jaiswal AK, et al. Substance use among medical students in Kathmandu valley. J Nepal Med Assoc. 2010;50(180):267-72. [PubMed | Full Text | DOI]

3. World Health Organization (WHO). Neuroscience of Psychoactive Substance Use and Dependence. Addiction. 2004;99(10):1361-2. [Full Text | DOI]

4. Rai D, Gaete J, Girotra S, Pal HR, Araya R. Substance use among medical students: Time to reignite the debate? Natl Med J India. 2008;21(2):75-8. [PubMed | Full Text]

5. Arora A, Kannan S, Gowri S, Choudhary S, Sudarasanan S, Khosla PP. Substance abuse amongst the medical graduate students in a developing country. Indian J Med Res. 2016 Jan;143(1):101-3. [PubMed | Full Text | DOI]

6. Smart RG, Hughes PH, Johnson LD, Anumonye A, Khant U, Medina Mora ME, et al. A methodology for student drug-use surveys. World Heal Organ Offset Publ. 1980. [Full Text]

7. Budhathoki N, Shrestha MK, Acharya N, Manandhar A. Substance use among third year medical students of Nepal. J Nepal Health Res Counc. 2010 Apr;8(1):15-8. [PubMed | Full Text]

8. Makanjuola AB, Daramola TO, Obembe AO. Psychoactive substance use among medical students in a Nigerian university. World Psychiatry. 2007 Jun;6(2):112-4. [PubMed | Full Text]

9. Tsvetkova LA, Antonova NA. The prevalence of drug use among university students in St. Petersburg, Russia. Psychol Russ State Art. 2013;6(1):86-94. [Full Text | DOI]

10. Jaiswal HS, Jain SL, Jaiswal SS. Patterns of Substance Use in First Year and Final year Medical Students: A Cross-sectional Study. Int J Recent Surg Med Sci 2017;3(2)98-101. [타ll Text | DOI]
11. Thapa N, Aryal KK, Puri R, Shrestha S, Shrestha S, Thapa P, et al. Alcohol consumption practices among married women of reproductive age in Nepal: A population based household survey. PLoS One. 2016;11(4):e0152535. [PubMed | Full Text I DOI]

12. Adhikari TB, Rijal A, Kallestrup P, Neupane D. Alcohol consumption pattern in western Nepal: Findings from the COBIN baseline survey. BMC Psychiatry. 2019;19(283). [Ful] Text | $\underline{\mathrm{DOI}}]$

13. Thapa N, Aryal KK, Paudel M, Puri R, Thapa P, Shrestha $S$, et al. Nepalese Homebrewed Alcoholic Beverages: Types, Ingredients, and Ethanol Concentration from a Nation Wide Survey. J Nepal Health Res Counc. 2015;13(29):59-65. [PubMed | Full Text]

14. Dhimal M, Bista B, Bhattarai S, Dixit LP, Hyder MKA, Agrawal N, et al. Report of Non Communicable Disease Risk Factors STEPS Survey Nepal 2019. Kathmandu: Nepal Health Research Council. 2020. [Full Text]

15. Alcohol Research: Current Reviews Editorial Staff. Drinking Patterns and Their Definitions. Alcohol Res. 2018;39(1):17-18. [PubMed | Full Text]

16. World Health Organization. Global status report on alcohol and health 2018: executive summary. World Heal Organ [Internet]. Geneva, World Health Organization; 2018 Sep 27 [cited 2021 Apr 10]. Available from: https://apps.who.int/ iris/handle/10665/274603. [Full Text]

17. Edenberg HJ. The genetics of alcohol metabolism: Role of alcohol dehydrogenase and aldehyde dehydrogenase variants. Alcohol Research and Health. 2007;30(1):5-13. [PubMed | Full Text]

18. WHO Department of Gender, women and Health. Gender, health and alcohol use [Internet]. Geneva: World Health Organization; 2005 Sep [cited 2021 Apr 20]. Available from: https://www.who.int/gender-equity-rights/knowledge/ alcoholfinal.pdf?ua $=1$. [Full Text] 
19. Ceylan-Isik AF, McBride SM, Ren J. Sex difference in alcoholism: Who is at a greater risk for development of alcoholic complication? Life Sciences. 2010 Jul 31;87(5-6):133-8. [PubMed | Full Text | DOI]

\section{(C) The Author(s) 2018}

This work is licensed under a Creative Commons Attribution 4.0 International License. The images or other third party material in this article are included in the article's Creative Commons license, unless indicated otherwise in the credit line; if the material is not included under the Creative Commons license, users will need to obtain permission from the license holder to reproduce the material. To view a copy of this license, visit http://creativecommons.org/licenses/by/4.0/ 